\title{
On the genomic regions associated with milk lactose in Fleckvieh cattle
}

\author{
Angela Costa, ${ }^{1}$ Hermann Schwarzenbacher, ${ }^{2}$ Gábor Mészáros, ${ }^{3 *}$ Birgit Fuerst-Waltll, ${ }^{3}$ Christian Fuerst, ${ }^{2}$ \\ Johann Sölkner, ${ }^{3}$ and Mauro Penasa ${ }^{1}$ \\ 'Department of Agronomy, Food, Natural resources, Animals and Environment, University of Padova, Viale dell'Università 16, \\ 35020 Legnaro (PD), Italy \\ ${ }^{2}$ ZuchtData EDV-Dienstleistungen GmbH, Dresdner Strasse 89/19, A-1200 Vienna, Austria \\ ${ }^{3}$ University of Natural Resources and Life Sciences Vienna (BOKU), Department of Sustainable Agricultural Systems, \\ Division of Livestock Sciences, Gregor Mendel-Strasse 33, A-1180 Vienna, Austria
}

\section{ABSTRACT}

Lactose is a sugar uniquely found in mammals' milk and it is the major milk solid in bovines. Lactose yield $(\mathrm{LY}, \mathrm{kg} / \mathrm{d})$ is responsible for milk volume, whereas lactose percentage (LP) is thought to be more related to epithelial integrity and thus to udder health. There is a paucity of studies that have investigated lactose at the genomic level in dairy cows. This paper aimed to improve our knowledge on LP and LY, providing new insights into the significant genomic regions affecting these traits. A genome-wide association study for LP and LY was carried out in Fleckvieh cattle by using bulls' deregressed estimated breeding values of first lactation as pseudo-phenotypes. Heritabilities of firstlactation test-day LP and LY estimated using linear animal models were 0.38 and 0.25 , respectively. A total of 2,854 bulls genotyped with a 54K SNP chip were available for the genome-wide association study; a linear mixed model approach was adopted for the analysis. The significant SNP of LP were scattered across the whole genome, with signals on chromosomes 1, 2, $3,7,12,16,18,19,20,28$, and 29 ; the top 4 significant SNP explained $4.90 \%$ of the LP genetic variance. The signals were mostly in regions or genes with involvement in molecular intra- or extracellular transport; for example, CDH5, RASGEF1C, ABCA6, and SLC35F3. A significant region within chromosome 20 was previously shown to affect mastitis or somatic cell score in cattle. As regards LY, the significant SNP were concentrated in fewer regions (chromosomes 6 and 14), related to mastitis/somatic cell score, immune response, and transport mechanisms. The 5 most significant SNP for LY explained $8.45 \%$ of genetic variance and more than one-quarter of this value has to be attributed to the variant within $A D G R B 1$. Significant peaks in target

Received March 21, 2019.

Accepted July 31, 2019.

*Corresponding author: gabor.meszaros@boku.ac.at regions remained even after adjustment for the 2 most significant variants previously detected on BTA6 and BTA14. The present study is a prelude for deeper investigations into the biological role of lactose for milk secretion and volume determination, stressing the connection with genes regulating intra- or extracellular trafficking and immune and inflammatory responses in dairy cows. Also, these results improve the knowledge on the relationship between lactose and udder health; they support the idea that LP and its derived traits are potential candidates as indicators of udder health in breeding programs aimed to enhance cows' resistance to mastitis.

Key words: lactose, genome-wide association study (GWAS), inflammatory response, molecular transport, bovine milk

\section{INTRODUCTION}

Lactose is the natural sugar present in milk of mammals and its concentration is predicted using mid-infrared spectroscopy in individual and bulk milk samples during routine recording schemes. Lactose percentage $(\mathbf{L P})$ is associated with udder health in cattle (Ebrahimie et al., 2018; Costa et al., 2019a); in fact, as soon as IMI and inflammation occur, milk LP decreases. Overall, moderate correlations between LP and SCS, the most adopted indicator of IMI worldwide, have been reported in the literature, with peaks of -0.44 (Stoop et al., 2007) and -0.66 (Vilas Boas et al., 2017) for genetic and phenotypic correlations, respectively. Moreover, Costa et al. (2019a) estimated a negative genetic correlation $(-0.18)$ between LP and mastitis in Fleckvieh $(\mathbf{F V})$ cows in early to mid lactation. In the presence of IMI, the permeability of epithelial cells changes and lactose is partly lost in the bloodstream (Bansal et al., 2005); this explains why plasma LP is an indicator of epithelial integrity in cattle (Herve et al., 2019). As regards lactose yield $(\mathbf{L Y})$, this trait is closely related to milk volume, because it is the major milk osmole; in 
fact, the amount of synthesized lactose directly determines water uptake in the alveoli (Fox et al., 2015). This means that the higher the LY upstream, the higher the milk yield. The ability to synthesize a high amount of lactose might be related to greater expression of genes encoding glucose transporters, which are responsible for glucose uptake from blood (Zhao, 2014), and also to greater blood sugar availability. The mammary gland is the first target tissue for the delivery of substrates as glucose; this supports the fact that the metabolic priority of dairy cows is milk synthesis and that the udder is subjected to homeorhesis (Bauman and Currie, 1980). Moreover, the Golgi is the cellular environment specialized for lactose synthesis, and greater genetic expression of its enzymes in mammary tissue could further affect LP, LY, or both. Despite this, little is known about the physiological and biological paths behind conversion of glucose to lactose in the mammary gland and the association of LP with mastitis or IMI. In fact, interest in this milk component has only recently increased in the scientific community (Sneddon et al., 2015, 2016; HaileMariam and Pryce, 2017; Costa et al., 2018, 2019b). Milk yield, and fat and protein content and yield are usually included in the most common routine genetic or genomic evaluation schemes in Europe and are thus the target phenotypes of genome-wide association studies (GWAS) in dairy cattle (Wang and Bovenhuis, 2018). Conversely, only a few GWAS for LP and LY have been performed in cattle (Lopdell et al., 2017; Wang and Bovenhuis, 2018). Thus, an opportunity exists to investigate genomic regions that affect LP and LY to better understand which genes influence these traits.

The FV breed has a share of about $75 \%$ of Austrian controlled dairy cows (ZAR, 2018), and a joint genetic evaluation is carried out for FV by Austria, Germany, and the Czech Republic. This cooperative system allows generation of both big data and accurate genomic $\mathrm{EBV}$, whose routine estimation was recognized by the International Committee for Animal Recording in 2011. Although LP and LY have recently been reported to be genetically associated with mastitis and ketosis in FV (Costa et al., 2019a), information on genomic regions affecting LP and LY is lacking for this breed. Therefore, in this study, we aimed to perform a GWAS to better understand the genetic background of LP and LY, and to evaluate accordance with genomic regions affecting udder health traits, such as mastitis, IMI, and SCS.

\section{MATERIALS AND METHODS}

\section{Genotypes}

Genomic data of 7,003 purebred FV bulls were jointly provided by Austria, Germany, and the Czech Republic. All individuals were genotyped with the $54 \mathrm{~K}$ Illumina BovineSNP50 BeadChip (Illumina Inc., San Diego, CA).

\section{Pseudo-Phenotypes}

The bulls' deregressed EBV of first lactation were used as pseudo-phenotypes in the GWAS. First, variance components and heritability of LP and LY (Table 1) were estimated using the VCE6 software, version 6.0 (Neumaier and Groeneveld, 1998). For this purpose, 198,038 test-day milk yield and infrared-predicted LP records of 54,878 cows representing a subset of the entire data $(>16$ million milk test-day records and $>1$ million cows) were used; LY was calculated as (LP/100 $\times$ milk yield). The single-trait test-day repeatability animal model included the fixed effects of region-yearmonth of sampling, herd-year-season of sampling, age at calving, and DIM (linear and quadratic covariate), and the random effects of permanent environment, additive genetic animal, and residual. Bulls' EBV for first lactation were then estimated using the MiX99 software (Lidauer et al., 2015) by applying the abovementioned model on all test-day records with reliable information on LP and LY ( $\mathrm{n}=7,065,937$; Table 1). The pedigree included 1,824,262 animals; that is, cows with phenotypic observations and all available generations of ancestors. A deregression was carried out based on the approach proposed by Jairath et al. (1998) and Schaeffer (2001), implemented in the software MiX99 (Lidauer et al., 2015). Finally, only bulls with an estimated daughter contribution $\geq 10$ were considered for further investigation, which led to 3,566 and 3,558 bulls for LP and LY, respectively.

Table 1. Descriptive statistics $\left(7,065,937\right.$ test-day records) and heritability ${ }^{1}$ of lactose percentage and lactose yield in first-parity cows

\begin{tabular}{lccccc}
\hline Trait & Mean & CV $(\%)$ & Minimum & Maximum & $\begin{array}{c}\text { Heritability } \\
\text { (SE) }\end{array}$ \\
\hline Lactose percentage (\%) & 4.86 & 3.29 & 4.00 & 5.49 & $0.38(0.01)$ \\
Lactose yield $(\mathrm{kg} / \mathrm{d})$ & 0.98 & 28.57 & 0.12 & 3.74 & $0.25(0.01)$ \\
\hline
\end{tabular}

${ }^{1}$ Estimated using a subset of 198,038 test-day records. 


\section{Quality Control}

The quality control was performed with the software PLINK 1.9 (Purcell et al., 2007; Chang et al., 2015). The quality of SNP was ensured by removing variants with call rate $<0.90$, minor allele frequency $<1 \%$, and deviating significantly $(P$-value $<1.00 \mathrm{E}-6)$ from HardyWeinberg equilibrium. A call rate $\geq 0.90$ was required for bulls to be included. After editing, 40,486 SNP and 2,854 bulls for LP, and 40,094 SNP and 2,853 bulls for LY were available for the GWAS.

\section{Association Study}

The linear mixed model approach implemented in GEMMA software (Zhou and Stephens, 2012) for the GWAS was

$$
\mathbf{y}=\mu+\mathbf{X} \beta+\mathbf{u}+\varepsilon,
$$

where $\mathbf{y}$ is the vector of phenotypes (deregressed EBV of LP or LY); $\mu$ is the intercept; $\mathbf{X}$ is a vector of marker genotypes; $\beta$ is the effect size of the markers; $\mathbf{u}$ is a vector of random individual effects; and $\varepsilon$ is a vector of errors. Log-likelihood ratio statistics were adopted to test the null hypothesis that a polymorphism did not affect the phenotype; that is, $\mathrm{H}_{0}: \beta=0$ was tested against $\mathrm{H}_{1}: \beta \neq 0$ for each SNP. In addition, the genomic relationship matrix was included in the analysis to account for population structure and avoid the presence of systematic bias. Because the Bonferroni correction is usually too restrictive and does not account for the fact that several SNP may trace the same QTL because of linkage disequilibrium (Goddard and Hayes, 2012), the false discovery rate with a cut-off at 0.20 ( $P$-value $<0.00013)$ was used as criterion to fulfill the $P$-value thresholds for significance discrimination (Efron, 2007). Graphical representations of Manhattan and quantilequantile plots were obtained in the $\mathrm{R}$ software using the "CMplot" (Yin, 2016) and "qqman" packages (Turner, 2018), respectively. The proportion of genetic variance explained by a target SNP (SNP-t) and its variants in linkage disequilibrium was derived in the GCTA software (Yang et al., 2011). In particular, genetic variance was estimated using 2 different genomic relationship matrices: one for the SNP-t (with variants in linkage disequilibrium) and one for the remaining SNP. Then, the proportion of variance explained by the SNP-t was derived as the ratio between the 2 variances. Finally, significant genes were identified on the National Center for Biotechnology Information website (https://www .ncbi.nlm.nih.gov/; NCBI, 2018) by mapping polymorphisms referring to the genome assembly ARS-UCD
1.2. "Nearby" genes were defined to be at most \pm 0.1 $\mathrm{Mb}$ distant from the significant SNP.

\section{RESULTS AND DISCUSSION}

\section{Lactose Percentage}

The significant variants detected in the GWAS for LP are listed in Table 2 and the quantile-quantile plot is shown in Figure 1. Within the genome, signals of LP were spread across several chromosomes (Figure 2), which confirms that LP is a polygenic trait controlled by multiple regions with cumulative effects (Goddard et al., 2016). The amount of genetic variance explained by the 4 most significant SNP was $4.90 \%$, of which onethird was attributed to ARS-BFGL-NGS-39978 $(P=$ 4.132E-08) that is close to $(\leq 0.1 \mathrm{Mb}) N E M P 2, N A B 1$, MFSD6, and LOC104971101 (BTA2). Table 3 provides an overview of genes detected and Table 4 summarizes their known major functions. Several polymorphisms were in mastitis and inflammation response-related regions; in particular, a variant $(154.087 \mathrm{Mb}, \mathrm{BTA} 1)$ was detected within the gene PLCL2, which includes leukocyte B proliferation and immune response regulation among its functions. Additionally, a significant SNP (15.526 Mb, BTA3) was detected near EFNA1, which encodes ephrin, a protein related to the inflammatory response in mammary cells and the integrity of mammary epithelial cells (Kang et al., 2018). The gene $A N K H$ in BTA20 was close to 2 significant variants previously detected by Tiezzi et al. (2015) in a GWAS for mastitis in first-parity US Holsteins. Similarly, Meredith et al. (2013) found variants within the window 57.65 to $57.75 \mathrm{Mb}$ of BTA20 that affected SCS in Holstein cows in Ireland. This was confirmed by Lopdell et al. (2017), who reported a significant signal for LP at $58.45 \mathrm{Mb}$ (BTA20). A significant polymorphism in BTA1 was found within $P A K 2$, regulator of signal transduction, and near NRROS, involved in immune response and oxidative activity. Significant signals, including that with the lowest $P$-value, were in the region from 5.75 to 6.70 $\mathrm{Mb}$ of BTA2, known to be related to transmembrane transport activity and including MFSD6, NEMP2, and $S L C 40 A 1$. In particular, among the functions of $M F S D 6$, it is worth mentioning the roles in reception of macrophages and facilitation of intra- or extracellular transport (NCBI, 2018). A SNP on BTA7 was within RASGEF1C, regulator of membrane-associated activity and vesicle trafficking. The $C D H 5$ gene, regulator of cell polarity, was detected on BTA18, whereas the membrane-associated protein $A B C A 6$ and the junction protein GJC1 were within BTA19. Among all functions of the $A B C A$ gene family, it is worth mentioning the 
molecular transport within and among cells, as for RASGEF1C (BTA7) and SLC35F3 (BTA28); moreover, $A B C A 6$ is related to leukocytes and antimicrobial activity (Wathes et al., 2019) and it has been found significant for mastitis in Holstein cows, together with its neighbors ( $A B C A 5, A B C A 9$, and $A B C A 10$; Tiezzi et al., 2015). The $K C N K 1$ gene was close to 2 signals on BTA28; it codes for proteins involved in potassium and sodium channel activities and for stabilization of membrane potential in epithelial cells. In addition, $K C N K 1$ is well expressed in mammary tissue and is related to mastitis in mice (Ogorevc et al., 2009). A couple of significant SNP on BTA20 were near $A N K H$, a mastitisrelated gene in Holsteins (Tiezzi et al., 2015). Finally, a few variants were within genes without functions related to either IMI or transport mechanisms: LOC112449084 and LOC784305 (BTA12), LOC101904639 (BTA16), and LOC112442737 (BTA19). These signals were also detected for LP by Lopdell et al. (2017) in Holstein and Jersey cows in New Zealand. The region within BTA19 (33.51 to $61.13 \mathrm{Mb}$ ), known to affect LP (Lopdell et al., 2017; Wang and Bovenhuis, 2018), was here picked up by 3 significant SNP, 2 of them located at 61.017 and $61.441 \mathrm{Mb}$, which were also neighboring the SNP (58.45 Mb) detected by Lopdell et al. (2017). The effect of BTA28 region (at around $6.56 \mathrm{Mb}$ ) was confirmed in the present study by the presence of 3 significant variants $(6.55$ to $6.89 \mathrm{Mb})$. The SNP on BTA29 (9.32 Mb) was not far from the one (9.61 Mb) detected by Lopdell et al. (2017), and Wang and Bovenhuis (2018). Finally, no signals were detected at $8.70 \mathrm{Mb}$ of BTA28 or 37.1
$\mathrm{Mb}$ of BTA6, both thought to significantly affect LP (Lopdell et al., 2017; Wang and Bovenhuis, 2018).

These findings make LP an interesting trait for genetic purposes in cattle and may be used to better understand causality between IMI and this milk component. In fact, the present GWAS helped increase the knowledge of the genetic architecture of such a complex trait, which relies on several factors such as blood glucose availability and uptake, blood-milk barrier (i.e., osmotic equilibrium), and the epithelial integrity of alveoli (i.e., udder health).

\section{Lactose Yield}

Findings related to GWAS for LY are shown in Table 5 and the quantile-quantile plot is reported in Figure 1. Visually, 2 major significant peaks were detected for LY (Figure 3); indeed, around $74 \%$ of significant variants were within BTA6 and BTA14, and the amount of genetic variance explained by the top 5 significant SNP was $8.45 \%$, with the variant within $A D G R B 1$ accounting for $2.44 \%$ (Figure 4 ). The latter is a regulator of transmembrane signaling receptor activity, promotor of microbicidal activity of macrophages and associated with udder morphology in cows (Marete et al., 2018), stressing the strong biological dependence of LY on udder health and immune response. The same variant was the most significant in a GWAS for mastitis (Wang et al., 2015) and for milk yield and fat and protein percentage in Chinese Holsteins (Wang et al., 2019). Sahana et al. (2013) found the above-mentioned SNP

Table 2. Significant SNP for deregressed EBV of lactose percentage, their position on Bos taurus autosomes, and $P$-values

\begin{tabular}{llrr}
\hline BTA & SNP & Position $(\mathrm{Mb})$ & $P$-value \\
\hline 1 & ARS-BFGL-NGS-5124 & 71.263427 & $9.293 \mathrm{E}-05$ \\
& Hapmap42521-BTA-35582 & 72.736590 & $4.123 \mathrm{E}-06$ \\
\multirow{2}{*}{2} & ARS-BFGL-NGS-95240 & 154.087389 & $3.260 \mathrm{E}-05$ \\
& ARS-BFGL-NGS-39978 & 5.757355 & $4.132 \mathrm{E}-08$ \\
3 & Hapmap49624-BTA-47893 & 6.700805 & $4.093 \mathrm{E}-05$ \\
7 & ARS-BFGL-NGS-64215 & 15.525599 & $4.367 \mathrm{E}-05$ \\
12 & ARS-BFGL-NGS-110962 & 1.009369 & $5.051 \mathrm{E}-07$ \\
& BTA-123122-no-rs & 69.319934 & $1.920 \mathrm{E}-07$ \\
& Hapmap50646-BTA-29027 & 70.140996 & $2.090 \mathrm{E}-05$ \\
16 & ARS-BFGL-NGS-57541 & 77.315938 & $9.680 \mathrm{E}-05$ \\
& ARS-BFGL-NGS-74373 & 51.811400 & $9.342 \mathrm{E}-05$ \\
18 & BTA-26576-no-rs & 67.703949 & $2.502 \mathrm{E}-05$ \\
19 & ARS-BFGL-NGS-119782 & 34.126956 & $2.138 \mathrm{E}-06$ \\
& ARS-BFGL-NGS-19774 & 44.547216 & $5.576 \mathrm{E}-05$ \\
& Hapmap25852-BTA-148919 & 61.016756 & $1.027 \mathrm{E}-05$ \\
20 & ARS-BFGL-NGS-55564 & 61.441042 & $1.371 \mathrm{E}-05$ \\
& BTB-01648514 & 58.240835 & $2.366 \mathrm{E}-06$ \\
28 & BTB-01648552 & 58.264762 & $9.257 \mathrm{E}-05$ \\
& BTB-00874839 & 6.547497 & $6.825 \mathrm{E}-05$ \\
\multirow{2}{*}{29} & BTB-00874898 & 6.575192 & $4.084 \mathrm{E}-07$ \\
& ARS-BFGL-NGS-40170 & 6.888276 & $1.618 \mathrm{E}-05$ \\
& Hapmap32898-BTA-66437 & 9.319793 & $4.730 \mathrm{E}-06$ \\
\hline
\end{tabular}


(a)

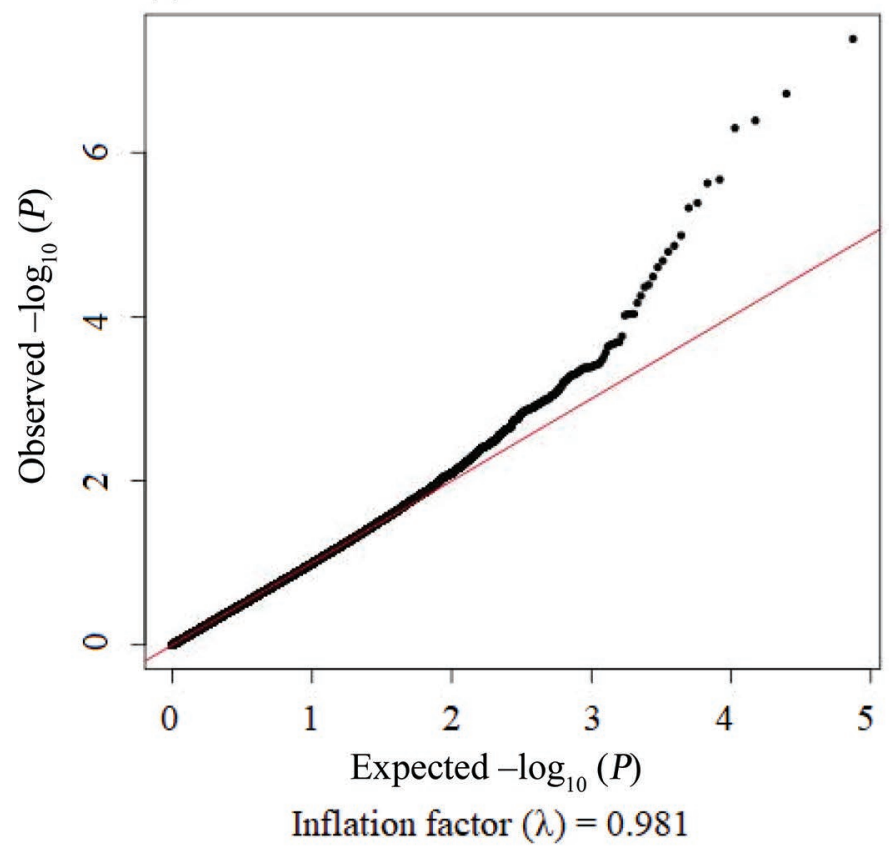

(b)

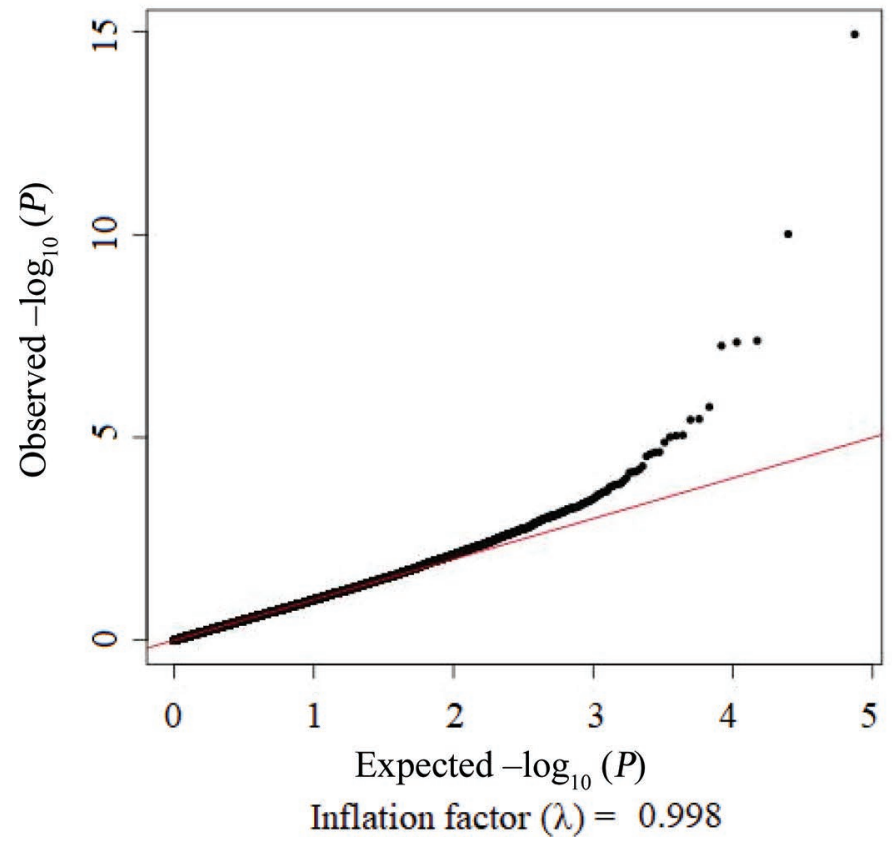

Figure 1. Quantile-quantile plot of the expected $P$-values under null hypothesis versus the observed $P$-values distribution for (a) lactose percentage, and (b) lactose yield.

to be significant for mastitis in second-parity cows. Interestingly, the DGAT1 gene was found to influence LY in the GWAS of Lopdell et al. (2017), based on the UMD3.1.1 assembly. Because the current GWAS was based on the ARS-UCD1.2 genome assembly, DGAT1 was not identified in this study; however, the presence of such a significant signal confirmed previous findings on the presence of significant QTL for LY around 1.77 Mb of BTA14 (tag variant rs134364612; Lopdell et al., 2017).

A list of all detected genes is provided in Table 3, with their main functions listed in Table 6 . Few regions on BTA6 and BTA14 are known to affect SCS and mastitis (Ogorevc et al., 2009; Wang et al., 2015). Within BTA6, several signals covered a region from 84.57 to $88.82 \mathrm{Mb}$, coincident to the window already reported to affect mastitis or SCS in US Holsteins (Cole et al., 2011), Nordic Holsteins (Sahana et al., 2013), Danish Holsteins (Wu et al., 2015), and German Holsteins (Abdel-Shafy et al., 2018). Furthermore, a variant in position $88.82 \mathrm{Mb}$ of BTA6 was very close to $C X C L 8$ $(88.81 \mathrm{Mb})$, a gene related to mastitis, IMI, immune and inflammatory responses, and neutrophil activation (Youngerman et al., 2004; NCBI, 2018). Moreover, this significant region (87.11 to $88.82 \mathrm{Mb}$, BTA6) included NPFFR2 (87.25 to $87.33 \mathrm{Mb}$ ), which is involved in macrophage activity stimulation, and it is related to udder health. In fact, several authors (Sahana et al., 2013; Wu et al., 2015; Cai et al., 2018) reported a relationship between mastitis and NPFFR2 in bovines. Pausch et al. (2016) found this gene to affect both the morphology of mammary gland and mastitis resistance in $\mathrm{FV}$ cows. Within the above-mentioned window of BTA6, 3 other important genes were detected: MGC152010, associated with blood NEFA and metabolic status of cow (Ha et al., 2015), and ANKRD17 and LOC781441, which are related to neutrophil count and activity and to glucuronosyltransferase activity, respectively. The gene $A N K R D 17$ was less than $0.1 \mathrm{Mb}$ from $C O X 18$, located in an area significant for SCS in dairy cows (Chen et al., 2015). The significant gene $S L C 4 A 4$ (also known as $N B C e 1$ ) is a sodium-cotransporter solute carrier, patented as a genetic marker for mastitis resistance (Yamaguchi and Ishikawa, 2008; Fang et al., 2017, 2018) and was flanking the region on BTA6 detected in this GWAS. Our results are supported by those of Fang et al. (2017), who reported a significant region for mastitis resistance at 88.84 and $88.72 \mathrm{Mb}$ (BTA6) for Holstein and Nordic Red cows, respectively. The variant Hapmap25708-BTC-043671 (87.11 Mb) was less than 1 $\mathrm{Mb}$ from $D C K$, which is related to udder health (Wu et al., 2015; Cai et al., 2018), milk protein (Strucken et al., 2012), and milk casein (Dadousis et al., 2017).

On BTA14, a significant SNP (4.34 Mb) was close to FAM135B, involved in cellular lipid metabolic processes, and COL22A1, a gene that was significant for milk and protein yield and fat percentage in the study of Jiang et al. (2010) in Chinese Holstein cows. Furthermore, on the same chromosome, the sugar transport regulating gene $S L C 45 A 4$ and a regulator of ketone body metabo- 
(a)

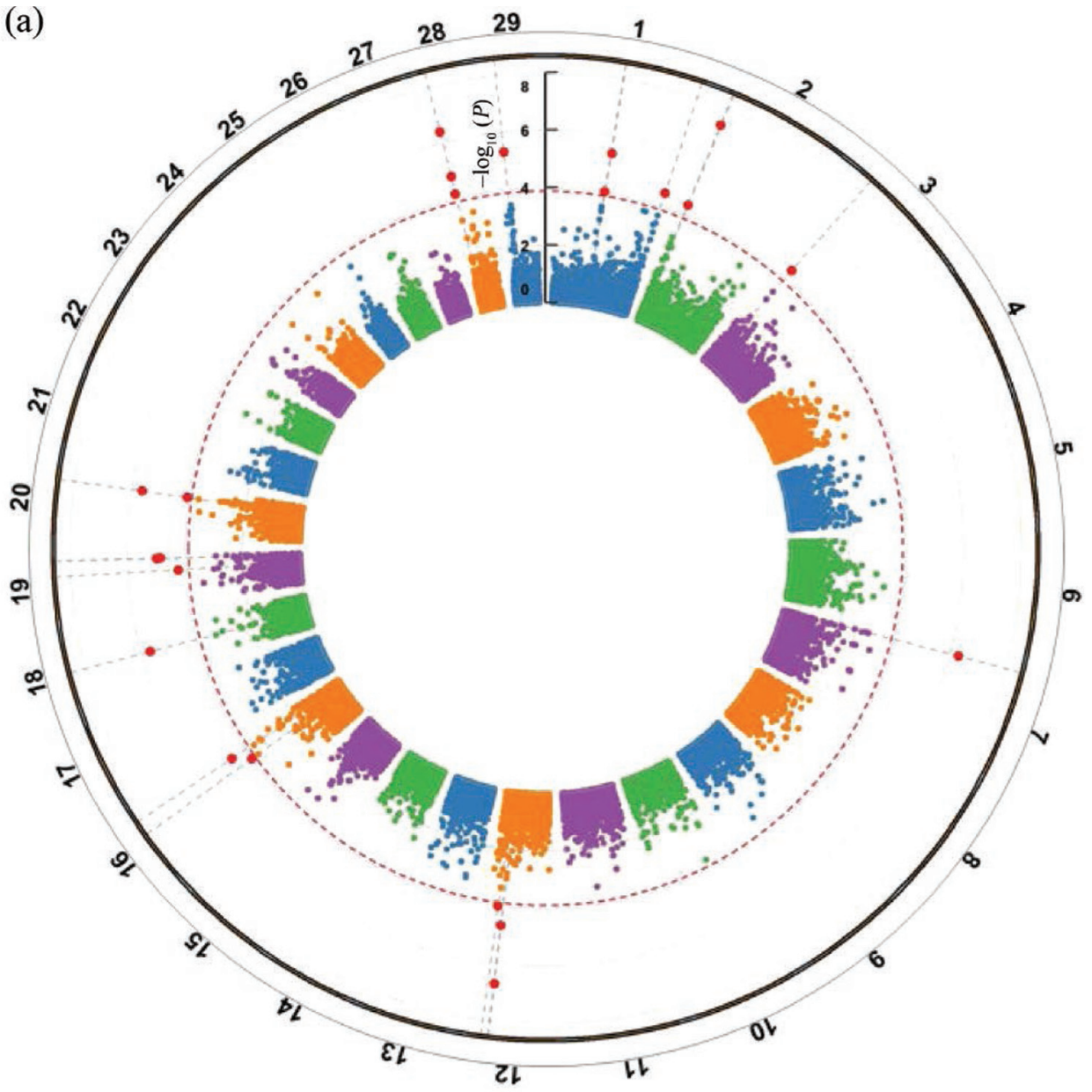

(b)

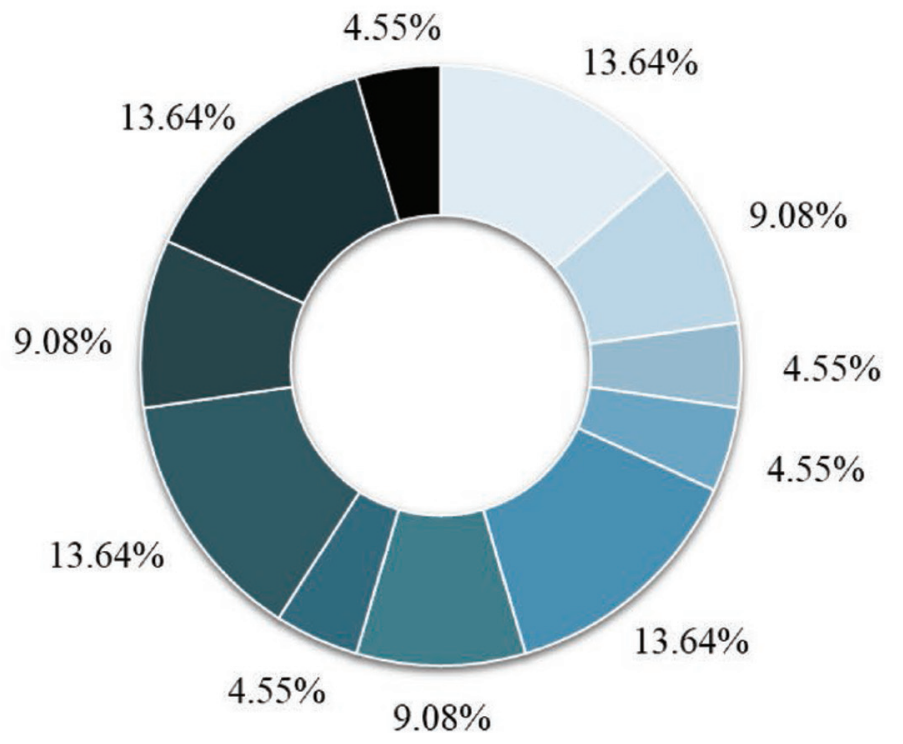

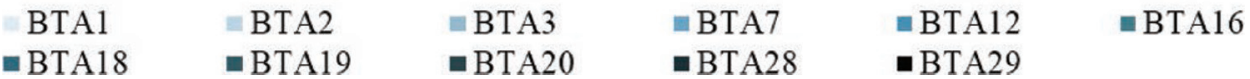

Figure 2. (a) Manhattan plot for lactose percentage, and (b) distribution of significant variants across BTA. The gray solid and red dashed lines in the Manhattan plots indicate BTA and false discovery rate threshold $(P<0.00013)$, respectively. 
Table 3. Gene harboring the SNP $\left(\mathrm{Gene}_{\mathrm{H}}\right)$ and nearby genes (left and right) for each significant SNP for lactose percentage (LP) and lactose yield (LY)

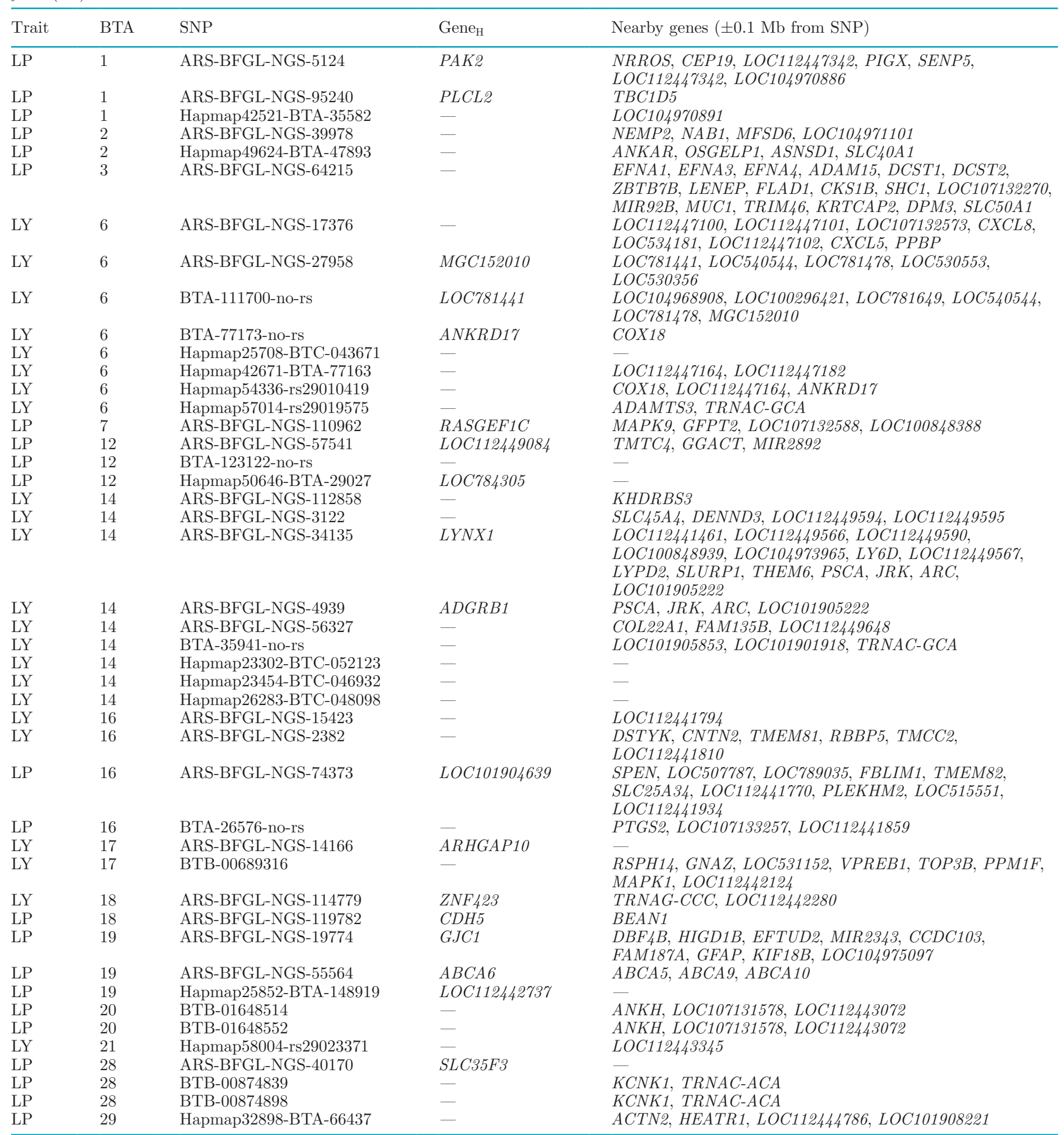

lism, DENND3, were both close to the variant ARSBFGL-NGS-3122 (Sigdel et al., 2017). According to Ogorevc et al. (2009), several mastitis and SCS-related regions are spread across the bovine genome and many are concentrated on BTA14; in fact, DENND3 was also significant in a GWAS of SCS in dairy cows (Chen et al., 2015). One significant variant was within $L Y N X 1$ and near LY6D, THEM6, PSCA, SLURP, and LYPD2; 
Table 4. Location and main functions of detected genes in genome-wide association study of lactose percentage (sources: Gene Cards, 2018, https://www.genecards.org/; NCBI, 2018)

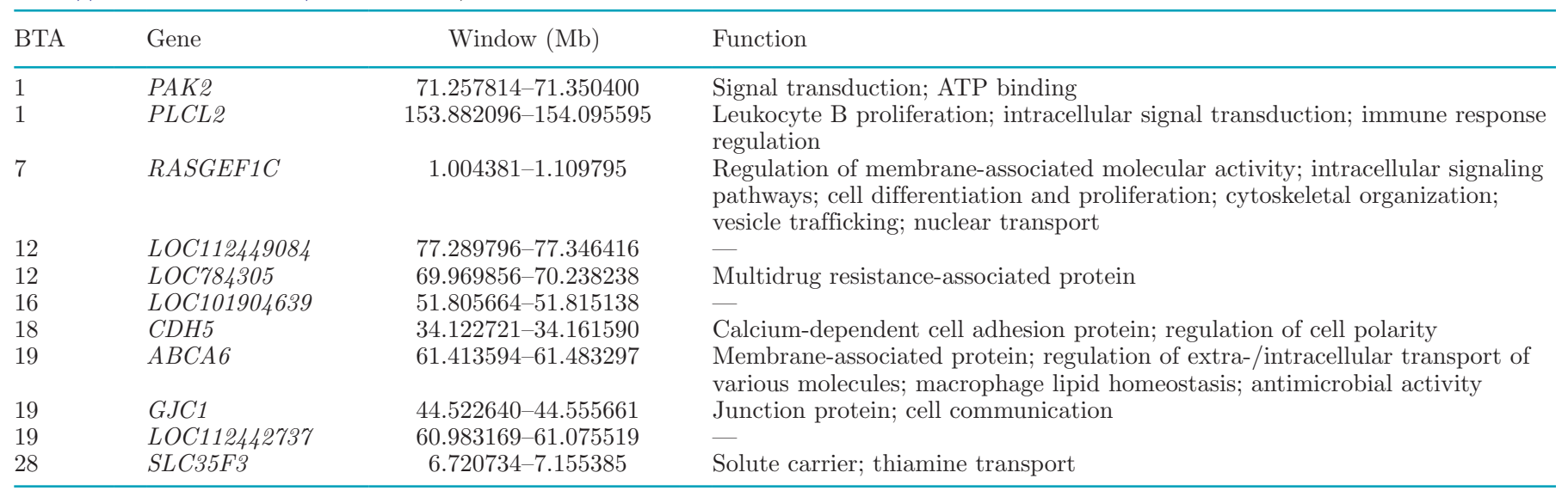

all of these genes overlapped with those reported by Tiezzi et al. (2015) for clinical mastitis in dairy cows and are involved in regulation of neutrophil activity. These genes are known as globally as the lymphocyteantigen-6 complex. This finding supported the idea that LY is strongly dependent on mammary epithelial cell number and functionality. It is worth noting that LY and mastitis are positively associated in FV cows (genetic correlation of 0.52; Costa et al., 2019a), suggesting that high-producing cows are more susceptible to IMI and udder health problems than low-producing cows. One variant was found within ARHGAP10, a gene related to mastitis resistance in cows (Kurz et al., 2019), whereas the transcription factor $Z N F 423$ was detected in BTA18. No coding genes were present in other significant regions of BTA16 and BTA17.

To adjust for the effects of the 2 highest significant signals for LY $(P$-value $<1.00 \mathrm{E}-10)$; that is, ARS-BFGL-NGS-4939 (BTA14) and Hapmap25708BTC-043671 (BTA6), and to check for the presence of effective causal variants, an additional GWAS was performed by fixing the 2 variants in the original model using GEMMA software (Zhou and Stephens, 2012). The significance of variants was checked following the

Table 5. Significant $\mathrm{SNP}^{1}$ for deregressed EBV of lactose yield, their position on Bos taurus autosomes, and $P$-value

\begin{tabular}{llcc}
\hline BTA & SNP & Position $(\mathrm{Mb})$ & $P$-value \\
\hline 6 & BTA-111700-no-rs & 84.575241 & $1.763 \mathrm{E}-06$ \\
& ARS-BFGL-NGS-27958 & 84.689991 & $3.652 \mathrm{E}-06$ \\
& Hapmap25708-BTC-043671 & 87.113639 & $9.683 \mathrm{E}-11$ \\
& Hapmap57014-rs29019575 & 87.801255 & $2.923 \mathrm{E}-05$ \\
& Hapmap42671-BTA-77163 & 88.006286 & $5.119 \mathrm{E}-05$ \\
& Hapmap54336-rs29010419 & 88.132026 & $9.712 \mathrm{E}-06$ \\
& BTA-77173-no-rs & 88.242415 & $1.319 \mathrm{E}-05$ \\
& ARS-BFGL-NGS-17376 & 88.822266 & $9.083 \mathrm{E}-06$ \\
& ARS-BFGL-NGS-34135 & 1.675278 & $4.123 \mathrm{E}-08$ \\
& ARS-BFGL-NGS-4939 & 1.801116 & $1.152 \mathrm{E}-15$ \\
& BTA-35941-no-rs & 2.276443 & $4.492 \mathrm{E}-08$ \\
& ARS-BFGL-NGS-3122 & 2.721633 & $6.219 \mathrm{E}-05$ \\
& ARS-BFGL-NGS-56327 & 4.336714 & $3.533 \mathrm{E}-06$ \\
& Hapmap23302-BTC-052123 & 4.848750 & $5.512 \mathrm{E}-08$ \\
& Hapmap23454-BTC-046932 & 5.831267 & $8.790 \mathrm{E}-06$ \\
& ARS-BFGL-NGS-112858 & 6.589274 & $2.578 \mathrm{E}-05$ \\
16 & Hapmap26283-BTC-048098 & 7.371252 & $7.145 \mathrm{E}-05$ \\
& ARS-BFGL- $N G S-2382$ & 2.933483 & $6.967 \mathrm{E}-05$ \\
17 & ARS-BFGL- $N G S-15423$ & 74.158269 & $2.290 \mathrm{E}-05$ \\
& ARS-BFGL-NGS-14166 & 10.283664 & $2.350 \mathrm{E}-05$ \\
21 & BTB-00689316 & 71.925055 & $7.369 \mathrm{E}-05$ \\
& ARS-BFGL-NGS-114779 & 18.192027 & $9.987 \mathrm{E}-05$ \\
& Hapmap58004-rs29023371 & 62.069305 & $1.146 \mathrm{E}-04$ \\
\hline
\end{tabular}

${ }^{1} \mathrm{SNP}$ in italics were significant in the additional genome-wide association study adjusted for the 2 most significant $(P$-value $<1.00 \mathrm{E}-10)$ variants: Hapmap25708-BTC-043671 and ARS-BFGL-NGS-4939. 


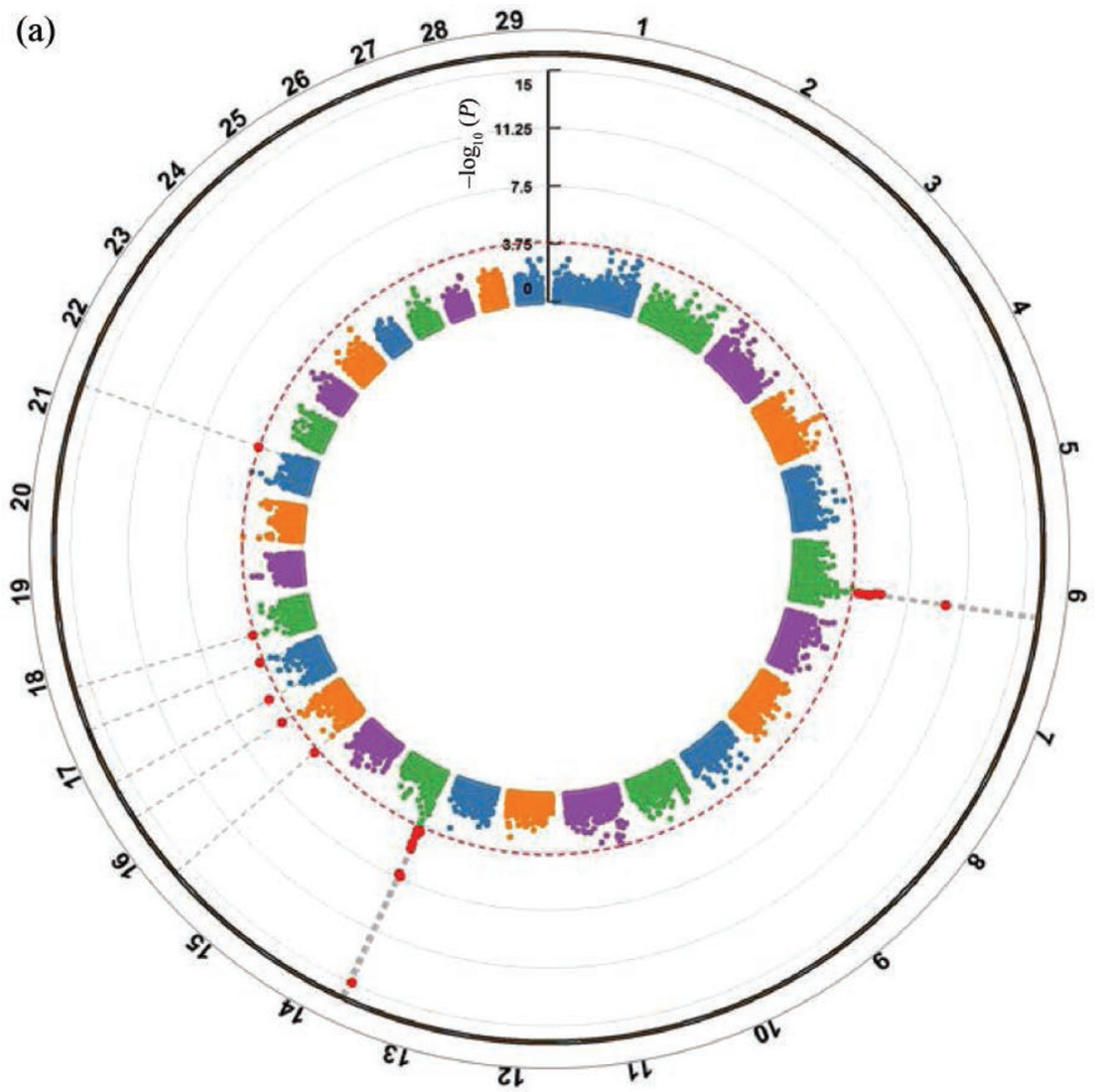

(b)

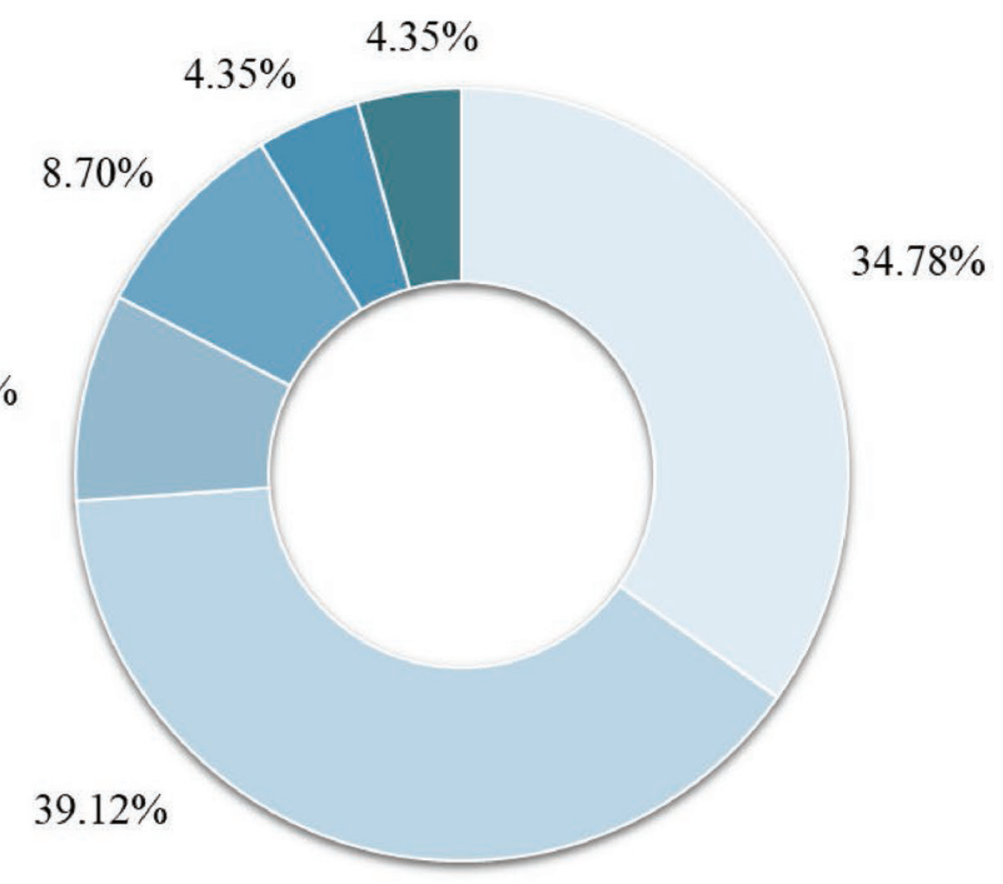

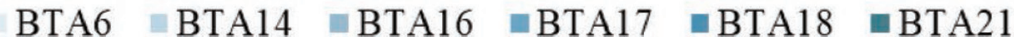

Figure 3. (a) Manhattan plot for lactose yield, and (b) distribution of significant variants across BTA. The gray solid and red dashed lines in the Manhattan plots indicate BTA and false discovery rate threshold $(P<0.00013)$, respectively. 
Table 6. Location and main functions of detected genes in genome-wide association study of lactose yield (sources: Gene Cards, 2018, https:/ /www.genecards.org/; NCBI, 2018)

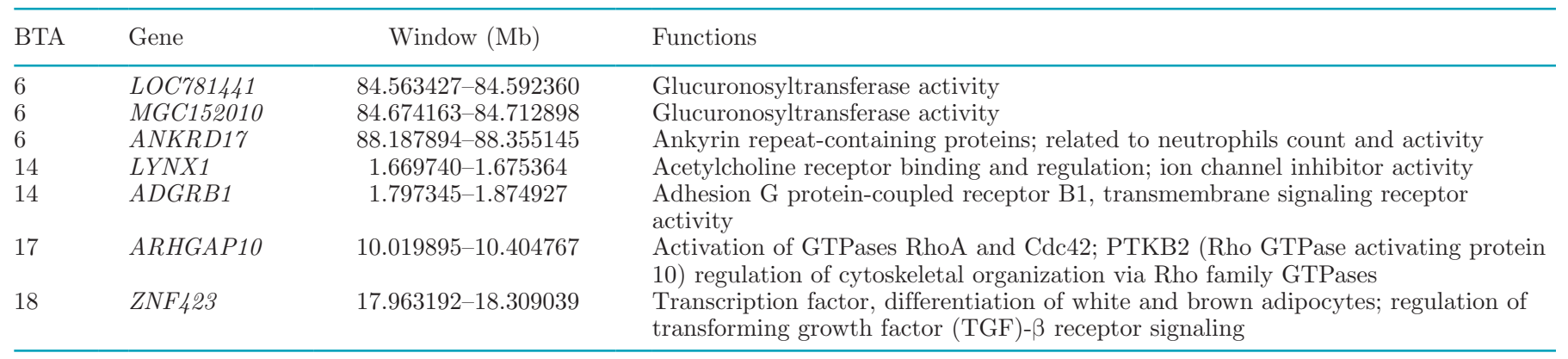

previously described criteria. Although the number of significant SNP decreased (Table 5), the significant regions detected mirrored those of previous GWAS, with the only exception of a new variant in a noncoding region of BTA20 (4.40 Mb), Hapmap54098-rs29010434. The smaller number of significant polymorphisms was expected, because the 2 strongest signals are thought to be in linkage disequilibrium with other neutral SNP and are also thought to affect the expression of other genes. However, these findings indicated the presence of multiple causal variants segregating in both BTA6 and BTA14 for LY.

\section{CONCLUSIONS}

In the present study, we report significant regions of the bovine genome affecting milk lactose in Fleckvieh

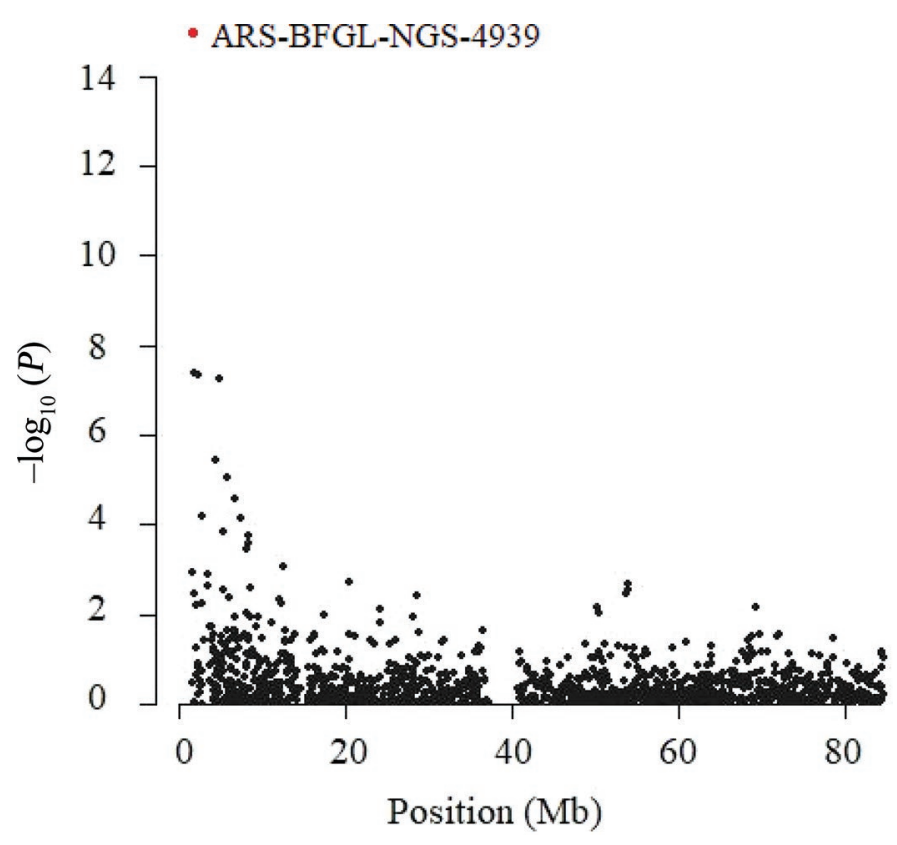

Figure 4. Manhattan plot focused on BTA14 of lactose yield with identification of the SNP (red dot) within ADGRB1. cattle, the major dairy breed in Austria. The ultimate goal of this study was to detect causal variants and overlapping regions with mastitis and SCS, because lactose percentage and its derived traits have the potential to be used as indicator traits in breeding programs to improve cow udder health. Signals of lactose percentage are scattered across several BTA and connected to some previously identified regions related to intra- or extracellular transport mechanisms, mastitis, and immune response. Conversely, the significant SNP for lactose yield are mainly concentrated on BTA6 and BTA14, always within or close to genes with functions related to transport mechanisms, mastitis, IMI, and inflammatory response. These findings highlight that lactose percentage is affected by several regions of the genome, whereas lactose yield is influenced by fewer regions with larger effects. Lactose yield and percentage do not share common regions, likely because of the different nature of these traits; in fact, the amount of lactose produced is only moderately genetically correlated with the final percentage in milk. Even though lactose percentage and yield are influenced by different regions of the genome, both traits have strong connections with intra- or extracellular transport mechanisms and immune response of dairy cows. Finally, some regions with unknown functions and not previously detected by other GWAS show high significance in the present study.

\section{ACKNOWLEDGMENTS}

This study was funded by the University of $\mathrm{Pa}$ dova (Ricerca Scientifica fondi DOR - 2017, project DOR1721792/17, Italy) and was conducted in collaboration with the COMET-Project D4Dairy, which is supported by Austrian Ministry for Transport, Innovation and Technology (BMVIT), the Federal Ministry for Digital and Economic Affairs (BMDW) of Austria, and the provinces of Lower Austria and Vienna. The first author gratefully acknowledges the Fondazione Ing. Aldo Gini (Padova, Italy) for funding the research 
period at University of Natural Resources and Life Sciences, Vienna (BOKU, Austria, Vienna).

\section{REFERENCES}

Abdel-Shafy, H., R. H. Bortfeldt, M. Reissmann, and G. A. Brockmann. 2018. Validating genome-wide associated signals for clinical mastitis in German Holstein cattle. Anim. Genet. 49:82-85. https: //doi.org/10.1111/age.12624.

Bansal, B. K., J. Hamann, N. T. Grabowski, and K. B. Singh. 2005. Variation in the composition of selected milk fraction samples from healthy and mastitic quarters, and its significance for mastitis diagnosis. J. Dairy Res. 72:144-152. https://doi.org/10.1017/ S0022029905000798.

Bauman, D. E., and W. B. Currie. 1980. Partitioning of nutrients during pregnancy and lactation: A review of mechanisms involving homeostasis and homeorhesis. J. Dairy Sci. 63:1514-1529. https:// doi.org/10.3168/jds.S0022-0302(80)83111-0.

Cai, Z., B. Guldbrandtsen, M. S. Lund, and G. Sahana. 2018. Prioritizing candidate genes post-GWAS using multiple sources of data for mastitis resistance in dairy cattle. BMC Genomics 19:656. https://doi.org/10.1186/s12864-018-5050-x.

Chang, C. C., C. C. Chow, L. C. Tellier, S. Vattikuti, S. M. Purcell, and J. J. Lee. 2015. Second-generation PLINK: Rising to the challenge of larger and richer datasets. Gigascience 4:7. https://doi .org/10.1186/s13742-015-0047-8.

Chen, X., C. Zhangrui, Z. Shujun, W. Dirk, and D. C. Wathes. 2015. Combining genome wide association studies and differential gene expression data analyses identifies candidate genes affecting mastitis caused by two different pathogens in the dairy cow. Open J. Anim. Sci. 5:358-393. https://doi.org/10.4236/ojas.2015.54040.

Cole, J. B., G. R. Wiggans, L. Ma, T. S. Sonstegard, T. J. Lawlor, B. A. Crooker, C. P. van Tassell, J. Yang, S. Wang, L. K. Matukumalli, and Y. Da. 2011. Genome-wide association analysis of thirtyone production, health, reproduction and body conformation traits in contemporary US Holstein cows. BMC Genomics 12:408. https: //doi.org/10.1186/1471-2164-12-408.

Costa, A., C. Egger-Danner, G. Mészáros, C. Fuerst, M. Penasa, J Sölkner, and B. Fuerst-Waltl. 2019a. Genetic associations of lactose and its ratios to other milk solids with health traits in Austrian Fleckvieh cows. J. Dairy Sci. https://doi.org/10.3168/jds 2018-15883.

Costa, A., B. Fuerst-Waltl, C. Fuerst, G. Mészáros, M. Penasa, and J. Sölkner. 2018. Genetic association between somatic cell score and milk lactose in early- to mid-lactation of first calving Fleckvieh cows. J. Cent. Eur. Agric. 19:791-797. https://doi.org/10.5513/ JCEA01/19.4.2347.

Costa, A., N. Lopez-Villalobos, G. Visentin, M. De Marchi, M. Cassandro, and M. Penasa. 2019b. Heritability and repeatability of milk lactose and its relationships with traditional milk traits, somatic cell score and freezing point in Holstein cows. Animal 13:909-916. https://doi.org/10.1017/S1751731118002094

Dadousis, C., S. Pegolo, G. J. M. Rosa, G. Bittante, and A. Cecchinato. 2017. Genome-wide association and pathway-based analysis using latent variables related to milk protein composition and cheesemaking traits in dairy cattle. J. Dairy Sci. 100:9085-9102. https://doi.org/10.3168/jds.2017-13219.

Ebrahimie, E., F. Ebrahimi, M. Ebrahimi, S. Tomlinson, and K. R Petrovski. 2018. A large-scale study of indicators of sub-clinical mastitis in dairy cattle by attribute weighting analysis of milk composition features: highlighting the predictive power of lactose and electrical conductivity. J. Dairy Res. 85:193-200. https://doi .org/10.1017/S0022029918000249.

Efron, B. 2007. Size, power and false discovery rates. Ann. Stat. 35:1351-1377. https://doi.org/10.1214/009053606000001460.

Fang, L., H. W. Lee, C. Chen, A. N. Harris, M. F. Romero, J. W. Verlander, and I. D. Weiner. 2018. Expression of the B splice variant of NBCe1 (SLC4A4) in the mouse kidney. Am. J. Physiol. Renal Physiol. 315:F417-F428. https://doi.org/10.1152/ajprenal .00515 .2017$.
Fang, L., G. Sahana, G. Su, Y. Yu, S. Zhang, M. S. Lund, and P. Sørensen. 2017. Integrating sequence-based GWAS and RNA-seq provides novel insights into the genetic basis of mastitis and milk production in dairy cattle. Sci. Rep. 7:45560. https://doi.org/10 $.1038 /$ srep45560.

Fox, P. F., T. Uniacke-Lowe, P. L. H. McSweeney, and J. A. O'Mahoni. 2015. Dairy Chemistry and Biochemistry. Springer International Publishing, Basel, Switzerland.

GeneCards. 2018. GeneCards: The Human Gene Database. Accessed Sep. 30, 2018. https://www.genecards.org/.

Goddard, M. E., K. E. Kemper, I. M. MacLeod, A. J. Chamberlain, and B. J. Hayes. 2016. Genetics of complex traits: Prediction of phenotype, identification of causal polymorphisms and genetic architecture. Proc. Biol. Sci. 283:20160569. https://doi.org/10.1098/ rspb.2016.0569.

Goddard, M. E., and B. J. Hayes. 2012. Genome-wide association studies and linkage disequilibrium in cattle. Pages 192-210 in Bovine Genomics. John Wiley \& Sons Inc., Hoboken, NJ.

Ha, N. T., J. J. Gross, A. van Dorland, J. Tetens, G. Thaller, M. Schlather, R. Bruckmaier, and H. Simianer. 2015. Gene-based mapping and pathway analysis of metabolic traits in dairy cows. PLoS One 10:e122325. https://doi.org/10.1371/journal.pone .0122325 .

Haile-Mariam, M., and J. E. Pryce. 2017. Genetic parameters for lactose and its correlation with other milk production traits and fitness traits in pasture-based production systems. J. Dairy Sci. 100:3754-3766. https://doi.org/10.3168/jds.2016-11952 (Corrigendum: J. Dairy Sci. 100:6008-6008. 10.3168/jds.2017-100-7-6008).

Herve, L., H. Quesnel, M. Veron, J. Portanguen, J. J. Gross, R. M. Bruckmaier, and M. Boutinaud. 2019. Milk yield loss in response to feed restriction is associated with mammary epithelial cell exfoliation in dairy cows. J. Dairy Sci. 102:2670-2685. https://doi.org/ 10.3168/jds.2018-15398.

Jairath, L., J. C. M. Dekkers, L. Schaeffer, Z. Liu, E. B. Burnside, and B. Kolstad. 1998. Genetic evaluation for herd life in Canada. J. Dairy Sci. 81:550-562. https://doi.org/10.3168/jds.S0022 -0302(98)75607-3.

Jiang, L., J. Liu, D. Sun, P. Ma, X. Ding, Y. Yu, and Q. Zhang. 2010. Genome wide association studies for milk production traits in Chinese Holstein population. PLoS One 5:e13661. https://doi.org/10 .1371/journal.pone.0013661.

Kang, M., W. Jeong, H. Bae, W. Lim, F. W. Bazer, and G. Song 2018. Bifunctional role of ephrin A1-Eph system in stimulating cell proliferation and protecting cells from cell death through the attenuation of ER stress and inflammatory responses in bovine mammary epithelial cells. J. Cell. Physiol. 233:2560-2571. https:/ /doi.org/10.1002/jcp.26131.

Kurz, J. P., Z. Yang, R. B. Weiss, D. J. Wilson, K. A. Rood, G. E. Liu, and Z. Wang. 2019. A genome-wide association study for mastitis resistance in phenotypically well-characterized Holstein dairy cattle using a selective genotyping approach. Immunogenetics 71:35-47. https://doi.org/10.1007/s00251-018-1088-9.

Lidauer, M., K. Matilainen, and I. Strandén. 2015. MiX99. General program for large mixed model problems with preconditioned conjugate gradient method. Release VIII/2015. Natural Resources Institute Finland (Luke), Jokioinen, Finland.

Lopdell, T. J., K. Tiplady, M. Struchalin, T. J. Johnson, M. Keehan, R. Sherlock, C. Couldrey, S. R. Davis, R. G. Snell, R. J. Spelman and M. D. Littlejohn. 2017. DNA and RNA-sequence based GWAS highlights membrane-transport genes as key modulators of milk lactose content. BMC Genomics 18:968. https://doi.org/10.1186/ s12864-017-4320-3.

Marete, A., M. S. Lund, D. Boichard, and Y. Ramayo-Caldas. 2018 A system-based analysis of the genetic determinism of udder conformation and health phenotypes across three French dairy cattle breeds. PLoS One 13:e0199931. https://doi.org/10.1371/journal .pone.0199931.

Meredith, B. K., D. Lynn, D. Berry, F. Kearney, D. Bradley, E. Finlay, and A. Fahey. 2013. A genome-wide association study for somatic cell score using the Illumina high-density bovine BeadChip identi- 
fies several novel QTL potentially related to mastitis susceptibility. Front. Genet. 4:229. https://doi.org/10.3389/fgene.2013.00229.

NCBI. 2018. Genome data viewer. Bos taurus ARS-UCD1.2. Accessed May 5, 2019. https://www.ncbi.nlm.nih.gov/assembly/GCF _002263795.1/.

Neumaier, A., and E. Groeneveld. 1998. Restricted maximum likelihood estimation of covariances in sparse linear models. Genet. Sel. Evol. 30:3-26. https://doi.org/10.1186/1297-9686-30-1-3.

Ogorevc, J., T. Kunej, A. Razpet, and P. Dovc. 2009. Database of cattle candidate genes and genetic markers for milk production and mastitis. Anim. Genet. 40:832-851. https://doi.org/10.1111/j .1365-2052.2009.01921.x.

Pausch, H., R. Emmerling, H. Schwarzenbacher, and R. Fries. 2016. A multi-trait meta-analysis with imputed sequence variants reveals twelve QTL for mammary gland morphology in Fleckvieh cattle. Genet. Sel. Evol. 48:14. https://doi.org/10.1186/s12711-016-0190 -4 .

Purcell, S., B. Neale, K. Todd-Brown, L. Thomas, M. Ferreira, D. Bender, J. Maller, P. Sklar, P. de Bakker, M. J. Daly, and P. C. Sham. 2007. PLINK: A tool set for whole-genome and populationbased linkage analyses. Am. J. Hum. Genet. 81:559-575. https:// doi.org/10.1086/519795.

Sahana, G., B. Guldbrandtsen, B. Thomsen, and M. S. Lund. 2013. Confirmation and fine-mapping of clinical mastitis and somatic cell score QTL in Nordic Holstein cattle. Anim. Genet. 44:620-626. https://doi.org/10.1111/age.12053.

Schaeffer, L. R. 2001. Multiple trait international bull comparison. Livest. Prod. Sci. 69:145-153. https://doi.org/10.1016/S0301 $-6226(00) 00255-4$.

Sigdel, A., C. K. Mak, R. Abdollahi-Arpanahi, K. Galvão, and F. Peñagaricano. 2017. Genome-wide association study for clinical mastitis, metritis, and ketosis in US Holstein cattle. J. Dairy Sci. 100(Suppl. 2):378. (Abstr.)

Sneddon, N. W., N. Lopez-Villalobos, S. R. Davis, R. E. Hickson, and L. Shalloo. 2015. Genetic parameters for milk components including lactose from test day records in the New Zealand dairy herd. N. Z. J. Agric. Res. 58:97-107. https://doi.org/10.1080/00288233 .2014 .978482 .

Sneddon, N. W., N. Lopez-Villalobos, R. E. Hickson, S. R. Davis, U. Geary, D. J. Garrick, and L. Shalloo. 2016. Dairy product production and lactose demand in New Zealand and Ireland under different simulated milk product-processing portfolios. Ir. J. Agric. Food Res. 55:126-135. https://doi.org/10.1515/ijafr-2016-0012.

Stoop, W. M., H. Bovenhuis, and J. A. M. van Arendonk. 2007. Genetic parameters for milk urea nitrogen in relation to milk production traits. J. Dairy Sci. 90:1981-1986. https://doi.org/10.3168/ jds.2006-434.

Strucken, E. M., R. H. Bortfeldt, J. Tetens, G. Thaller, and G. A. Brockmann. 2012. Genetic effects and correlations between production and fertility traits and their dependency on the lactationstage in Holstein Friesians. BMC Genet. 13:108. https://doi.org/ 10.1186/1471-2156-13-108.

Tiezzi, F., K. L. Parker-Gaddis, J. B. Cole, J. S. Clay, and C. Maltecca. 2015. A genome-wide association study for clinical mastitis in first parity US Holstein cows using single-step approach and genomic matrix re-weighting procedure. PLoS One 10:e0114919. https://doi.org/10.1371/journal.pone.0114919.

Turner, S. D. 2018. qqman: An R package for visualizing GWAS results using Q-Q and Manhattan plots. J. Open Source Softw. 3:731. https://doi.org/10.21105/joss.00731.
Vilas Boas, D. F., A. E. Vercesi Filho, M. A. Pereira, L. C. Roma Junior, and L. El Faro. 2017. Association between electrical conductivity and milk production traits in dairy Gyr cows. J. Appl. Anim. Res. 45:227-233. https://doi.org/10.1080/09712119.2016 .1150849 .

Wang, D., C. Ning, J. F. Liu, Q. Zhang, and L. Jiang. 2019. Short communication: Replication of genome-wide association studies for milk production traits in Chinese Holstein by an efficient rotated linear mixed model. J. Dairy Sci. 102:2378-2383. https://doi.org/ $10.3168 /$ jds.2018-15298.

Wang, Q., and H. Bovenhuis. 2018. Genome-wide association study for milk infrared wave numbers. J. Dairy Sci. 101:2260-2272. https:// doi.org/10.3168/jds.2017-13457.

Wang, X., P. Ma, J. Liu, Q. Zhang, Y. Zhang, X. Ding, L. Jiang, Y. Wang, Y. Zhang, D. Sun, S. Zhang, G. Su, and Y. Yu. 2015. Genome-wide association study in Chinese Holstein cows reveal two candidate genes for somatic cell score as an indicator for mastitis susceptibility. BMC Genet. 16:111. https://doi.org/10.1186/ s12863-015-0263-3.

Wathes, D. C., L. Buggiotti, M. Salavati, H. Takeda, and E. Gplus. Consortium. 2019. RNA-Seq analysis of whole blood from early lactation dairy cows reveals changes in leukocyte gene expression associated with circulating IGF1. Page 170 in Proc. Br. Soc. Anim. Sci., Advances in Animal Biosciences. Br. Soc. Anim. Sci., Penicuik, UK. Accessed May 20, 2019. https://www .cambridge.org/core/services/aop-cambridge-core/content/view/ 1E725FEC9443C13E5F36D90B9A693683/S2040470019000013a .pdf/proceedings_of_the_british_society_of_animal_science.pdf.

Wu, X., M. S. Lund, G. Sahana, B. Guldbrandtsen, D. Sun, Q. Zhang, and G. Su. 2015. Association analysis for udder health based on SNP-panel and sequence data in Danish Holsteins. Genet. Sel. Evol. 47:50. https://doi.org/10.1186/s12711-015-0129-1.

Yamaguchi, S., and T. Ishikawa. 2008. The electrogenic $\mathrm{Na}^{+}-\mathrm{HCO} 3$ cotransporter NBCe1-B is regulated by intracellular $\mathrm{Mg}^{2+}$. Biochem. Biophys. Res. Commun. 376:100-104. https://doi.org/10 .1016/j.bbrc.2008.08.104.

Yang, J., S. Hong Lee, M. E. Goddard, and P. M. Visscher. 2011. GCTA: A tool for genome-wide complex trait analysis. Am. J. Hum. Genet. 88:76-82. https://doi.org/10.1016/j.ajhg.2010.11 .011 .

Yin, L. 2016. User manual for CMPLOT - Circular Manhattan plot. https://cran.r-project.org/web/packages/CMplot/CMplot.pdf.

Youngerman, S. M., A. M. Saxton, S. P. Oliver, and G. M. Pighetti. 2004. Association of CXCR2 polymorphisms with subclinical and clinical mastitis in dairy cattle. J. Dairy Sci. 87:2442-2448. https: //doi.org/10.3168/jds.S0022-0302(04)73367-6.

ZAR (Zentrale Arbeitsgemeinschaft österreichischer Rinderzüchter). 2018. Jahresbericht 2017. Accessed Aug. 1, 2018. http://www.zar .at/Downloads/Jahresberichte/ZAR-Jahresberichte.html.

Zhao, F. Q. 2014. Biology of glucose transport in the mammary gland. J. Mammary Gland Biol. Neoplasia 19:3-17. https://doi.org/10 .1007/s10911-013-9310-8.

Zhou, X., and M. Stephens. 2012. Genome-wide efficient mixed-model analysis for association studies. Nat. Genet. 44:821-824. https:// doi.org/10.1038/ng.2310. 